\section{THU0229 DNA HYPOMETHYLATION AND DECREASED HYDROXYMETHYLATION IS ASSOCIATED WITH DECREASED ANTIOXIDANT RESPONSE IN SYSTEMIC LUPUS ERYTHEMATOUS PATIENTS}

E. Grau Garcia ${ }^{1}$, C.M. Feced Olmos ${ }^{1}$, M. Fernandez Matilla ${ }^{2}$, E. Labrador Sánchez $^{1}$, F.M. Ortiz-Sanjuan ${ }^{1}$, N. Fernández-Llanio ${ }^{2}$, K. Arévalo Ruales ${ }^{1}$, R. Negueroles Albuixech ${ }^{1}$, J. Ivorra Cortes ${ }^{1}$, J.J. Fragio Gil ${ }^{1}$, I. Martínez Cordellat ${ }^{1}$, R. González Mazarío ${ }^{1}$, I. Chalmeta Verdejo ${ }^{1}$, L. Gonzalez Puig ${ }^{1}$, C. Alcañiz Escandell ${ }^{1}$, C. Nájera Herranz ${ }^{1}$, I. Cánovas Olmos ${ }^{1}$, E. Vicens Bernabeu $^{1}$, J.E. Oller Rodriguez ${ }^{1}$, J.A. Castellano Cuesta ${ }^{2}$, V. Fornés Ferrer ${ }^{3}$, D. Hervás Marín ${ }^{3}$, L. Olivares González ${ }^{4}$, R. Rodrigo Nicolás ${ }^{4}$, J.A. Román Ivorra ${ }^{1} .{ }^{1}$ Rheumatology Department, HUP la Fe; ${ }^{2}$ Rheumatology Section, Hospital Arnau de Vilanova; ${ }^{3}$ Biostatistics Unit; ${ }^{4}$ Molecular, Cellular and Genomic Biomedicine, IIS la Fe, Valencia, Spain

Background: Systemic lupus erythematous (SLE) shows increased DNA demethylation. An intermediate step to DNA demethylation is the DNA hydroxymethylation, where $5-\mathrm{mC}$ is oxidized into $5-\mathrm{hmC}$. Hydroxymethylation is not completely understood and it may be related to oxidative stress in SLE patient. Objectives: To analyze the association between the hydroxymethylation and demethylation, with the antioxidant response and SLE pathophysiology. Methods: We analyzed in 142 SLE patients and 34 healthy controls the serum concentration of glutathione (GSH) and glutathione disulphide (GSSG) by UPLCMS/MS, superoxide dismutase (SOD) and total antioxidant capacity (TAC) by colorimetric methods. $5-\mathrm{mC}$ and 5 -hmC levels were measured by colorimetric methods. Complete blood-test was made and clinical data by personal interview was collected. Biostatistical analysis with R (3.3.2.) was performed.

Results: There is a correlation between the methylation and hydroxymethylation rate $(P<0.001)$, and both were lower in patients than in controls $(P=0.024$; $P<0.001)$. GSH and GSSG values were lower in patients $(P=0.033$ y $P=0.003)$, but GSH/GSSG ratio was not statistically different in both groups. SOD levels were higher in patients $(P=0.001)$, but TAC did not show significant differences. Higher demethylation is associated to lower TAC values in patients and healthy controls $(P=0.005 ; P=0.01)$. In patients, decreased SOD values are associated with higher demethylation and lower hydroxymethylation rates $(P<0.001 ; P=0.007)$. SOD and TAC levels are increased in SLE patients with higher demethylation and lower hydroxymethylation $(P=0.001 ; P<0.001)$. We did not observe any association between $5-\mathrm{mC}$ or 5 -hmC levels and GSH, GSSG or GSH/GSSG ratio. Higher demethylation is associated to vascular symptoms (defined by RELESSER study) and lupus anticoagulant ( $A L)$ positivity $(P=0.041 ; P=0.015)$, and lower hydroxymethylation to mucocutaneous damage (defined by RELESSER study) and $A L$ positivity $(P=0.015 ; P=0.009)$. Lower levels of $G S H$ and $G S S G$ were associated to increased accumulated damage assessed by SLICC ( $P=0.01$; $\mathrm{P}=0.005)$, and lower $\mathrm{SOD}$ values with longer disease duration $(\mathrm{P}=0.001)$.

Conclusions: We observed higher demethylation and lower hydroxymethylation in SLE patients than in controls, related to increased SOD activity. Moreover higher demethylation leads to lower TAC levels. These epigenetic disorders are related to antioxidant response disruptions in SLE patients, probably because of the chronic inflammatory condition. Our results suggest that epigenetic processes are involved in SLE physiopathology.

Acknowledgements: Financial support by GVA (GV15/83) is acknowledged.

Disclosure of Interest: None declared

DOI: 10.1136/annrheumdis-2017-eular.2905

\section{THU0230 HIF1A (RS11549465) AND AKNA (RS10817595) GENE POLYMORPHISMS ARE ASSOCIATED WITH PRIMARY SJÖGREN'S SYNDROME}

G. Hernandez-Molina ${ }^{1}$, J.M. Rodríguez-Pérez ${ }^{2}$, J. Fernández-Torres ${ }^{3}$, G. Lima ${ }^{1}$, N. Pérez-Hernández ${ }^{2}$, A. López-Reyes ${ }^{3}$, G.A. Martínez-Nava ${ }^{3}$ ${ }^{1}$ Immunology and Rheumatology, Instituto Nacional de Ciencias Medicas y Nutricion Salvador Zubiran; ${ }^{2}$ Department of Molecular Biology, Instituto Nacional de Cardiologia; ${ }^{3}$ Synovial Fluid Laboratory, Instituto de Rehabilitacion, Mexico City, Mexico

Background: HIF-1 $\alpha$ is the main transcriptional regulator of cellular and developmental response to hypoxia, and also participates in the integration of the T cell receptor and cytokine receptor-mediated signals of CD4+ helper cells. Another transcription factor also involved in the immune responses is the AT-hook transcription factor (AKNA).

Objectives: To evaluate the allele and genotype frequencies of polymorphic sites of HIF1A and ANKA genes in primary Sjögren's syndrome (pSS).

Methods: We included 110 patients with pSS and 141 ethnically matched healthy controls. Three HIF1A gene polymorphisms (Pro582Ser, Ala588Thr, and C191T) and two AKNA genes polymorphism (-1372C >A, and Pro624Leu) were genotyped using TaqMan probes in a Real-Time PCR instrument. Associations between pSS and genotypes, alleles and inheritance models of the SNPs of interest were evaluated by logistic regression adjusted by age and gender.

Results: Most of the patients were females (95.4\%), median age 55 years and median disease duration of 7.8 years. The $C / T$ genotype and the $T$ allele of the HIF1A Pro582Ser polymorphism protected against pSS (OR=0.22; $95 \%$ $\mathrm{Cl}=0.09-0.52 ; P<0.01 ;$ and $\mathrm{OR}=0.26 ; 95 \% \mathrm{Cl}=0.12-0.58 ; P<0.01$; respectively). Whereas under a recessive model adjusted by age and gender, the AKNA
$-1372 C>A$ polymorphism $A / A$ genotype was associated with an increased risk of pSS $(\mathrm{OR}=2.60 ; 95 \% \mathrm{Cl}=1.11-6.12 ; P=0.03)$. Parotid enlargement was associated with the HIF1A gene polymorphism (rs11549465), conferring protection for the $\mathrm{C} / \mathrm{T}$ genotype vs. $\mathrm{C} / \mathrm{C}(\mathrm{OR}=0.22 ; 95 \% \mathrm{Cl} 0.05-0.90, P=0.03)$. The allele T of the same polymorphism was also associated with parotid enlargement $(\mathrm{OR}=0.24$, $95 \% \mathrm{Cl}=0.65-0.95 ; P=0.04)$. We did not find any association with any other clinical or serological feature.

Conclusions: We identified HIF1A Pro582Ser $T$ allele and $C / T$ genotype as well as $A K N A-1372 C>A$ polymorphism $\mathrm{A} / \mathrm{A}$ genotype as genetic factors associated with pSS. Further studies in other populations are needed to validate our findings and to shed some light on their functional implications.

References:

[1] Palazon A, Goldrath A, Nizet V, Johnson R. HIF transcription factors, inflammation and immunity. Immunity 2014; 41:518-28.

[2] Sims-Mourtada JC, Bruce S, McKeller MR, et al. The human AKNA gene expresses multiple transcripts and protein isoforms as a result of alternative promoter usage, splicing, and polyadenylation. DNA Cell Biol 2005;24:325-38.

Disclosure of Interest: None declared

DOI: 10.1136/annrheumdis-2017-eular.2406

\section{THU0231 IL-17 POLARIZATION OF MAIT CELLS DERIVE FROM THE ACTIVATION OF TWO DIFFERENT PATHWAYS}

G. Guggino ${ }^{1}$, F. Ciccia ${ }^{2}$, M. Lo Pizzo ${ }^{2}$, D. Di Liberto ${ }^{2}$, L. Saieva ${ }^{2}$, P. Ruscitti ${ }^{2}$ P. Cipriani ${ }^{3}$, G. Sireci ${ }^{2}$, R. Alessandro ${ }^{2}$, F. Dieli ${ }^{2}$, R. Giacomelli ${ }^{3}$, G. Triolo ${ }^{2}$. 'DIBIMIS; ${ }^{2}$ University of Palermo, palermo; ${ }^{3}$ University of L'Aquila, L'Aquila, Italy

Background: Primary Sjogren Syndrome (pSS) is a chronic inflammatory disorder affecting exocrine glands. Both IL-23 and the downstream cytokines IL-17 and IL-22 are recognised as key players in the disease. Therefore, the identification of the cellular sources and inducers of $\mathrm{IL}-17$ is crucial in the understanding of the drivers of inflammation in pSS. Mucosal-associated invariant T (MAIT) cells recognize riboflavin derivatives presented by the MHC class I-like molecule MR1. Objectives: Recently, MAIT cells have been implicated in the pathogenesis of autoimmune disorders and found expanded in salivary glands of pSS patients. Their expression of IL7R and IL23R, makes them potential contributors to the pathogenesis of pSS

Methods: Mononuclear cells from 16 patients with pSS and 14 subjects with non Sjogren Syndrome secca syndrome (nSS) were isolated from blood and salivary glands. We assessed the phenotype and cytokine expression of MAIT cells by surface and intracellular flow cytometry analysis. The function of MAIT cells was assessed upon in vitro stimulation with recombinant IL-7, IL-23 or their specific ligand lumazine (a Vitamin B2 precursor previously reported to be recognized by and specifically activate MAIT cells).

Results: MAIT cells were reduced in frequency in peripheral blood but not in minor salivary glands of patients with pSS, compared with nSS. In vitro stimulation of MAIT cells from pSS patients induced cytokine production which was dependent on priming with IL-7, IL-23 or specific antigen (lumazine) stimulation. Particularly, IL-7 and IL-23 guarantee IL-17 polarization of MAIT cells by two different pathways via the activation of STAT3 or RORc respectively.

Conclusions: This study confirms a potential role for MAIT cells in pSS and, for the first time, links IL-7 and IL-23 to the IL-17 polarization of MAIT cells in these patients.

Disclosure of Interest: None declared

DOI: 10.1136/annrheumdis-2017-eular.5885

\section{THU0232 INHIBITING THE ACTIVATION OF COMPLEMENT C5 BY MESENCHYMAL STEM CELLS IN THE TREATMENT OF LUPUS NEPHRITIS}

H.-J. Ma ${ }^{1,2}$, C. Liu ${ }^{1}$, Z.-Y. Zhang ${ }^{1}$, R.-H. Feng ${ }^{1}$, W.-C. Li ${ }^{1}$, L.-Y. Sun ${ }^{1}$ ${ }^{1}$ Department of Rheumatology, The Affiliated Drum Tower Hospital of Nanjing University Medical School, Nanjing; ${ }^{2}$ Department of Rheumatology, The First Affiliated Hospital of Xinxiang Medical University, Weihui, China

Background: Excess activation of the complement system is involved in the development and progression of systemic lupus erythematosus (SLE). Allogeneic umbilical cord mesenchymal stem cells (UC-MSC) transplantation has achieved good clinical efficacy for refractory SLE, however, the exact mechanism is unclear. Our previous work found that deposits of $\mathrm{C} 5 \mathrm{a}$ and $\mathrm{C} 5 \mathrm{~b}-9$ were significantly enhanced in severe lupus nephritis (LN), which suggested that antagonists of $\mathrm{C5}$ might contribute to the treatment of $L N$, in other words, effective therapy for $L N$ may be involved in inhibiting the activation of $\mathrm{C} 5$.

Objectives: To observe the clinical effect of UC-MSC on SLE model mice (B6.Ipr), and explore the mechanism of MSC inhibiting the activation of complement C5 in lupus mice.

Methods: 26-week-old female B6.Ipr mice were randomly allocated in four groups, which were given the following treatments, CTX $(200 \mathrm{mg} / \mathrm{kg})$, UC-MSC $\left(1 \times 10^{6}\right)$, C5aRa $(\mathrm{W}-54011,1 \mathrm{mg} / \mathrm{kg})$, and an equal volume of $0.5 \% \mathrm{DMSO} .24$ hours urine and peripheral blood were collected periodically. All mice were sacrificed at 40 weeks of age.Urine protein to creatinine ratio was used to estimate daily urine protein excretion. Plasma creatinine was measured by a biochemical analyzer. Plasma levels of C3, C5a, soluble C5b-9, and anti-dsDNA 